Original Research Paper

\title{
Correlates of Resistance to Gastro-Intestinal Parasites Infection in South African Communal Indigenous Goat Populations
}

\author{
Takalani Judas Mpofu, Khathutshelo Agree Nephawe and Bohani Mtileni \\ Department of Animal Sciences, Tshwane University of Technology, Private Bag X680, Pretoria, 0001, South Africa
}

\author{
Article history \\ Received: 20-04-2020 \\ Revised: 17-06-2020 \\ Accepted: 01-07-2020 \\ Corresponding Author: \\ Takalani Judas Mpofu \\ Department of Animal \\ Sciences, Tshwane University \\ of Technology, Private Bag \\ X680, Pretoria, 0001, South \\ Africa \\ Email: MpofuTJ@tut.ac.za
}

\begin{abstract}
The study was conducted to investigate the correlates of resistance to Gastro-Intestinal Parasites (GIPs) infection in South African communal indigenous goat. A total of 288 goats were randomly sampled for fecal and blood collection. Infection intensity was estimated through determining the fecal egg per gram using a modified McMaster technique. Packed Cell Volume (PCV), Hemoglobin (Hgb) and Mean Corpuscular Hemoglobin $(\mathrm{MCH})$ were determined through Auto-Haematology-Analyser BC-2800Vet ${ }^{\circledR}$. Goat diagnosed free from GIP egg during coprologic evaluation were classified as uninfected, those whose Fecal Egg Count (FEC) were less than 800 as Low Fecal Count (LFEC) phenotype, those with FEC between 800 and 1200 as Intermediate Fecal Egg Count (IFEC) and those that were higher than 1200 as High Fecal Egg Count (HFEC) phenotype. Data were subjected to one-way ANOVA analyses, for dual coinfection, not all comparisons were possible. Pearson's moment correlation test was computed to determine the relationship between variables. The HFEC phenotyped goats were highly $(p<0.05)$ infected by GIPs followed by intermediate and lastly by LFEC phenotype. Higher $(\mathrm{p}<0.05) \mathrm{Hgb}(10.26$ $\mathrm{g} / \mathrm{dL}), \mathrm{PCV}(28.51 \%)$ and $\mathrm{MCH}(6.12 \mathrm{pg})$ were observed in uninfected goats compared to IFEC and HFEC phenotypes. A significant effect of infection status on $\mathrm{Hgb}$ and PCV was observed, however, $\mathrm{MCH}$ was not influenced $(p>0.05)$. There was a negative relationship $(p<0.05)$ between the Hgb and overall FEC, strongyles and Trichuris spp. intensity. Negative relationship $(\mathrm{p}<0.05)$ between PCV and overall FEC and all the GIPs except for Moniezia spp. intensity was evident. The $\mathrm{MCH}$ depicted a negative relationship $(\mathrm{p}<0.05)$ with Eimeria and Trichuris spp. intensity. The interactions between concomitant GIPs complicates the clinical outcome of infected goats and should be taken into consideration in any study that investigates disease under field conditions. The FECs, Hgb, PCV and $\mathrm{MCH}$ are correlates and potential selection criteria of GIP resistant goats.
\end{abstract}

Keywords: Capra hircus, Hemoglobin Concentration, Mean Corpuscular Hemoglobin, Packed Cell Volume, Strongyle, Trichuris spp.

\section{Introduction}

Goats (Capra hircus) are found to be highly susceptible to Gastro-Intestinal Parasite (GIP) infections (Singh et al., 2017; Mpofu et al., 2020) often leading to clinical diseases and loss of productivity (Risso et al., 2015; Rodríguez et al., 2015) and in extreme conditions, even death (Jegede et al., 2015). The most prevalent GIPs affecting goats in Africa are the Strongyloides papillosus, Monezia, Trichuris, Eimeria spp. and strongyles, especially the Homonchus contortus, Trichostrongylus spp. belonging to the order Strongylida (Blackie, 2014; Verma et al., 2018; Mpofu et al., 2020). Their prevalence varies with location/agro-ecological zones and ranges up to $90 \%$ and have been documented in various studies in Africa (Adeyemi et al., 2017; Zvinorova, 2017; Hassan et al., 2019; Squire et al., 2019; Mpofu et al., 2020). The primary control strategy for the 
GIP infections is the use of anthelmintic drugs (Maqbool et al., 2017), which is not sustainable because the GIP, especially the nematodes, develop anthelminthic drug resistance more quickly (Kelley et al., 2016; Erez and Kozan, 2018). The increasing prevalence of anthelmintic resistance in GIPs suggests that reliance on chemotherapy is unsustainable, therefore, alternative control measures to either reduce or eliminate the current dependency on chemotherapy are needed. A relatively simple and cheap method of reducing the effects of GIPs infection would be the selection and breeding of genetically GIP resistant animals (Baker, 1999; Bishop and Stear, 1999).

The natural variation in resistance to GIP infections is under genetic control (Benavides et al., 2016; Aboshady et al., 2020). The resistance is associated with variation in the key genes that control the immune system (Stear et al., 2004; Bressani et al., 2014). Several potential indicators such as parasitological, immunological and pathological (hematological parameters) phenotypic markers can be used to evaluate resistance to GIPs (Dominik, 2005). Parameters such as Fecal Egg Count (FEC) (Hayward et al., 2014) and Packed Cell Volume (PCV) (Saddiqi et al., 2012; Zvinorova, 2017) have been found to be repeatable, heritable, responsive to selection and simplest indicators of blood-sucking parasites. The FEC heritability as a measure of resistance ranges between 0.14 and 0.40 depending on both nematode species and breed surveyed (Gruner et al., 2004; Bishop and Morris, 2007). Resistant goats tend to have lower FECs, by approximately 50\% (González et al., 2011; Zvinorova, 2017) than the susceptible goats. The FECs should not be used as a stand-alone diagnostic tool to determine the severity of parasite infection (Hepworth et al., 2006; Saddiqi et al., 2012), other resistance phenotypic indicators should also form part of the diagnostic tool for resistance. Most of the GIPs (especially strongyles) are active blood suckers, the heavy parasitic burden often results in anemia (Burden et al., 2010). Packed cell volume, hemoglobin $(\mathrm{Hgb})$ concentration and Mean Corpuscular Hemoglobin $(\mathrm{MCH})$ are substantive indices in the diagnosis of anemia (Awodi et al., 2005; Chineke et al., 2006; Peters et al., 2011), therefore, can be used as response phenotypic predictors of GIPs infection intensity and whether an animal is resistant or not. Animals with lower values are considered anemic (Aster, 2004; Peters et al., 2011) as the clinical sign of high parasite infection. However, there is a paucity of information on the use of $\mathrm{Hgb}$ concentration and $\mathrm{MCH}$ as phenotypic predictors for GIP infection intensity in ruminants.

There is currently a paucity of information on the resistance and resilience status of the South African communal goats to GIPs as well as reliable phenotypic markers, correlates of such resistance and resilience. With a view to identifying reliable phenotypic markers that can be used as selection criteria for the GIP resistant animals, this research was therefore conducted to investigate the correlates of resistance to GIPs infection in South African communal goat populations.

\section{Materials and Methods}

\section{Ethical Approval}

The study was approved by the Animal Research Ethic Committee of the Faculty of Science, Tshwane University of Technology [FCRE 2017/10/01 (02) (SCI)].

\section{Study Site}

A total of 288 South African indigenous goats (male $=101$ and female $=274$ ) were randomly sampled in a longitudinal study during winter (June - July) and summer (November - December) in communal areas of the Kwa-Zulu Natal, Limpopo and Mpumalanga provinces, South Africa. The sample size was determined using Equation 1 (Thrusfield, 1997), the required sample size was calculated to be 288 goats for each set of the season. The animals were kept under extensive grazing systems where during the day they were released to graze on communal lands and kraaled at night. Goats were naturally infected with the GIP when grazing and there was no artificial infection of the GIP to goats. The flocks considered were those with no history of GIP treatment. The flocks were classified by age as an adult (>2 years), young goat (1-2 years) and suckling kids (<1 year) as described by Kheirandish et al. (2014):

$n=\frac{1.96^{2} p q}{L^{2}}$

where, $n=$ sample size, $p=$ expected prevalence, $q=1-p$ and $L=$ limits of error on the prevalence. Because the prevalence in the local goat population was unknown, the hypothesized prevalence of $75 \%$ was used with a $5 \%$ limit of error of the prevalence.

\section{Sample Collection}

About $10 \mathrm{~g}$ of fecal and $10 \mathrm{~mL}$ blood samples of each sampled animal were obtained directly from the rectum and the jugular vein, respectively. The collected fecal samples were placed into airtight containers and labelled, whilst, the blood samples were collected by venipuncture into the EDTA VACUETTE® tubes and labeled. Samples were kept between $2-4^{\circ} \mathrm{C}$ in cooler boxes prior and later refrigerated prior to analyses and transported to the laboratory for further coprological and hematological examination within $24 \mathrm{~h}$.

\section{Fecal Sample Analyses}

The fecal samples were subjected to a quantitative examination of the GIPs. The FEC measured as egg 
(EPG) or Oocyst Per Gram (OPG) was determined through a modified McMaster technique as described by Hansen and Perry (1994) in the positive fecal samples. Briefly, approximately $2 \mathrm{~g}$ of feces were placed in a beaker. Then $50 \mathrm{~mL}$ of floatation fluid was poured into the beaker containing $2 \mathrm{~g}$ of feces and mixed thoroughly. The resulting fecal suspension was poured through a tea strainer into another beaker. After rough shaking, $200 \mu \mathrm{L}$ was withdrawn and run into the counting chambers. About 1 minute between preparation and counting was allowed for the eggs or oocysts to float to the top of the slide, placed on a microscope slide and examined under the microscope $(\times 10)$. Three (3) samples were counted for each animal and the mean EPG or OPG of feces was calculated. The floatation fluid used was $\mathrm{NaCl}$. The GIPs were identified under a compound microscope (x10) based on the morphological appearance and size of helminth eggs and protozoa cysts and trophozoites (Foriet, 1999; Zajac and Conboy, 2006). The fecal samples were ground into five drops of bloat guard to prevent bubbles when counting the eggs, each count was multiplied by 100 and give an estimation number of eggs in the animal system (Aumont et al., 2003). Fecal cultures were prepared by incubating 2-3 g of feces between $26-28^{\circ} \mathrm{C}$ for 7 days at $80 \%$ humidity after which infective larvae were collected using a modified Baerman technique. L3-stage nematodes were identified according to the protocol proposed by Van Wyk et al. (2004). Eimeria species were identified following the sporulation of oocysts within the feces in a thin layer of $2.5 \%$ potassium dichromate for 1 week between 26$28^{\circ} \mathrm{C}$. The identification of Eimeria species was based on morphological characteristics of oocysts (size, shape, color and presence or absence of a micropyle and its cap). The $\mathrm{PCV}, \mathrm{Hgb}$ concentration and $\mathrm{MCH}$ were estimated using an Auto Haematology Analyzer BC2800Vet ${ }^{\circledR}$ (Shenzhen Mindray Bio-Medical Electronics Co., Ltd, Hamburg, Germany).

\section{Study Design}

To be consistent with epidemiological terminologies, in this study, the intensity is defined as the total number of worms in a host digestive system, the intensity is zero when a host has no GIP (Cattadori et al., 2008) and this contrasts with the definition suggested by Bush et al. (1997). After the sample analysis, animals were categorically assigned into four respective response phenotypes namely, uninfected group, Low FEC (LFEC), Intermediate FEC (IFEC) and High FEC (HFEC) phenotype based on their individual FEC as described by Asha and Chebo (2015) with slight modification. Goats diagnosed free from any of the GIP egg or oocyst during the coprological evaluation were classified as uninfected, those whose FEC did not exceed 800 as LFEC phenotype, those that exceed 1200, as HFEC phenotype and those with FEC between 800 and 1200 as IFEC. For dual co-infection, very few animals were co-infected with Eimeria and Moniezia spp., S. papillosus and Moniezia spp., Moniezia and Trichuris spp., not all comparisons were possible, only three dual co-infections were possible in addition to three single infections.

\section{Statistical Analysis}

The FECs for all GIPs found were transformed through a base 10 logarithm $\left(\log _{10} \mathrm{FEC}+25\right)$ to approximate a normal distribution. The transformed data were used for statistical analysis. The infection intensity and hematological parameters data were subjected to one-way ANOVA analyses through the MiniTab 17 (2017). The FEC transformed data and the results were then back-transformed by taking anti-logarithms and presented as geometric means. Means were separated using Fisher's Protected LSD test $(\mathrm{p}<0.05)$. Pearson's moment correlation test was computed to determine the relationship between the hematological parameters and FECs of individual GIPs $(\mathrm{p}<0.05)$.

\section{Results}

The mean FEC and hematological parameters of South African communal goats segregated into LFEC, IFEC and HFEC phenotypes are presented in Table 1. The results indicate a highly significant difference $(\mathrm{p}<0.05)$ in the FECs for strongyles, S. papillosus, Trichuris, Eimeria and Moniezia, spp. within the phenotypes. The pattern of the FECs intensity depicted that HFEC phenotyped goats were highly $(\mathrm{p}<0.05)$ infected by the strongyles, S. papillosus, Trichuris, Eimeria and Moniezia, spp. followed by intermediate and lastly by LFEC phenotype.

Results also indicated that the difference between the $\mathrm{Hgb}$ concentration, $\mathrm{PCV}$ and $\mathrm{MCH}$ was highly significant $(\mathrm{p}<0.05)$ between the phenotypes. The uninfected goats had higher Hgb concentration (10.26 g/dL), PCV (28.51\%) and $\mathrm{MCH}(6.12 \mathrm{pg})$ compared to the intermediate (Hgb concentration: $9.17 \mathrm{~g} / \mathrm{dL}, \mathrm{PCV}: 25.45 \%, \mathrm{MCH}: 5.20 \mathrm{pg}$ ) and HFEC (Hgb concentration: $8.40 \mathrm{~g} / \mathrm{dL}$, PCV: $23.15 \%$, $\mathrm{MCH}: 5.20 \mathrm{pg}$ ) phenotypes. However, the PCV and $\mathrm{MCH}$ of the uninfected group were similar $(p>0.05)$ to that of the LFEC phenotyped goats. The Hgb concentration of LFEC $(8.17 \mathrm{~g} / \mathrm{dL})$ and HFEC $(8.40 \mathrm{~g} / \mathrm{dL})$ phenotypes was similar ( $p>0.05)$. The HFEC phenotyped goats had lower values of the $\mathrm{Hgb}$ concentration $(8.40 \mathrm{~g} / \mathrm{dL}), \mathrm{PCV}$ (23.15\%) and $\mathrm{MCH}$ (4.81 pg), respectively.

The impact of infection status (single vs co-infection) on hematological parameters of South African communal goats are presented in Table 2. There was a significant $(\mathrm{p}<0.05)$ effect of the infection status on the $\mathrm{Hgb}$ concentration and $\mathrm{PCV}$, however, the $\mathrm{MCH}$ was not influenced $(p>0.05)$. Goats co-infected with strongyles 
and Moniezia spp., strongyles and Trichuris spp. resulted in lower $(\mathrm{p}<0.05) \mathrm{Hgb}$ concentration (strongyles and Moniezia spp.: 8.71 and strongyles and Trichuris spp.: 8.64), PCV (strongyles and Moniezia spp.: 32.71 and strongyles and Trichuris spp.: 26.89) and $\mathrm{MCH}$ (strongyles and Moniezia spp.: 31.24 and strongyles and Trichuris spp.: 31.19) compared to those co-infected with strongyles and S. papillosus and the single infections.

Pearson's moment correlation test between the GIPs intensity and the hematological parameters in South African communal goats are presented in Table 3. There was a significant negative relationship between the $\mathrm{Hgb}$ concentration and overall FEC (rp $=-0.45, \mathrm{p}<0.01$ ), strongyles $(\mathrm{rp}=-0.52, \mathrm{p}<0.01)$ and Trichuris $\mathrm{spp}$. $(\mathrm{rp}=$ $-0.66, \mathrm{p}<0.001)$. However, the Hgb concentration depicted insignificant negative relationship with S. papillosus $(\mathrm{rp}=-$
0.06, p>0.05), Eimeria spp. $(\mathrm{rp}=-0.07, \mathrm{p}>0.05)$ and the positive insignificant relationship with Moniezia spp. ( $\mathrm{rp}=$ $0.02, \mathrm{p}>0.05)$. There was also a significant negative relationship between the PCV and overall FEC ( $\mathrm{rp}=-0.55$, $\mathrm{p}<0.01$ ), strongyles $(\mathrm{rp}=-0.70, \mathrm{p}<0.001)$, Trichuris $(\mathrm{rp}=$ $-0.59, \mathrm{p}<0.01)$, S. papillosus ( $\mathrm{rp}=-0.39, \mathrm{p}<0.05)$ and Eimeria spp. $(\mathrm{rp}=-0.26, \mathrm{p}<0.05)$, however, insignificant positive relationship between the PCV and Moniezia spp. $(\mathrm{rp}=0.17, \mathrm{p}>0.05)$ was observed. The MCH depicted also a significant negative relationship with overall FEC (rp = $-0.13, \mathrm{p}<0.05)$, Eimeria $(\mathrm{rp}=-0.50, \mathrm{p}<0.01)$ and Trichuris spp. $(\mathrm{rp}=-0.21, \mathrm{p}<0.05)$. A significant positive relationship between MCH and Moniezia spp. $(\mathrm{rp}=0.19$, $\mathrm{p}<0.05)$ was observed, however, the insignificant negative relationship was also noticed between the $\mathrm{MCH}$ and strongyles (rp = $-0.12, \mathrm{p}>0.05)$ and S. papillosus $(\mathrm{rp}=-0.14, \mathrm{p}>0.05)$.

Table 1: Mean ( \pm SE) egg per gram of gastro-intestinal parasites and hematological parameters of South African communal indigenous goats

\begin{tabular}{lllll}
\hline & & Fecal egg count response phenotypes \\
Parameters & Uninfected goats & Low FEC & Intermediate FEC & High FEC \\
\hline Overall FEC & 0 & $504.66^{\mathrm{c}} \pm 14.1$ & $1021.85^{\mathrm{b}} \pm 19.8$ & $1654.13^{\mathrm{a}} \pm 20.7$ \\
Strongyles & 0 & $208.05^{\mathrm{c}} \pm 14.4$ & $415.97^{\mathrm{b}} \pm 20.2$ & $560.55^{\mathrm{a}} \pm 21.1$ \\
Strongyloides papillosus & 0 & $75.42^{\mathrm{c}} \pm 11.0$ & $129.41^{\mathrm{b}} \pm 15.6$ & $257.80^{\mathrm{a}} \pm 16.2$ \\
Trichuris & 0 & $79.66^{\mathrm{c}} \pm 12.1$ & $152.10^{\mathrm{b}} \pm 17.0$ & $243.12^{\mathrm{a}} \pm 17.8$ \\
Eimeria & 0 & $69.92^{\mathrm{c}} \pm 11.4$ & $165.55^{\mathrm{b}} \pm 16.1$ & $300.00^{\mathrm{a}} \pm 16.8$ \\
Moniezia & 0 & $71.61^{\mathrm{c}} \pm 9.27$ & $158.82^{\mathrm{b}} \pm 13.1$ & $292.66^{\mathrm{a}} \pm 13.6$ \\
Hemoglobin concentration (g/dL) & $10.26^{\mathrm{a}} \pm 0.19$ & $8.71^{\mathrm{bc} \pm 0.28}$ & $9.17^{\mathrm{b}} \pm 0.27$ & $8.40^{\mathrm{c}} \pm 0.28$ \\
PCV (\%) & $28.51^{\mathrm{a}} \pm 0.41$ & $27.95^{\mathrm{a}} \pm 0.57$ & $25.45^{\mathrm{b}} \pm 0.60$ & $23.15^{\mathrm{b}} \pm 0.59$ \\
MCH (pg) & $6.12^{\mathrm{a}} \pm 0.17$ & $5.63^{\mathrm{ab}} \pm 0.24$ & $5.20^{\mathrm{bc}} \pm 0.25$ & $4.81^{\mathrm{c}} \pm 0.25$ \\
\hline
\end{tabular}

$\overline{\mathrm{a}, \mathrm{b}, \mathrm{c}}$ Row means with different superscripts differs significantly $(p<0.05)$; FEC: Fecal Egg Count; PCV: Packed Cell Volume; MCH: Mean Corpuscular Hemoglobin

Table 2: Impact of infection status (single vs dual co-infection) on hematological parameters of communal indigenous goats Hematological parameters

\begin{tabular}{llll} 
Infection status & Hemoglobin concentration $(\mathrm{g} / \mathrm{dL})$ & $\mathrm{PCV}(\%)$ & $\mathrm{MCH}(\mathrm{pg})$ \\
\hline Strongyles & $9.84^{\mathrm{a}} \pm 0.36$ & $25.63^{\mathrm{a}} \pm 1.52$ & $6.11^{\mathrm{a}} \pm 0.59$ \\
Strongyloides papillosus & $9.69^{\mathrm{a}} \pm 0.74$ & $25.22^{\mathrm{a}} \pm 1.52$ & $6.10^{\mathrm{a}} \pm 1.01$ \\
Trichuris & $9.28^{\mathrm{a}} \pm 0.62$ & $23.31^{\mathrm{b}} \pm 1.27$ & $6.09^{\mathrm{ab}} \pm 0.87$ \\
Strongyles/Strongyloides papillosus & $9.94^{\mathrm{a}} \pm 0.50$ & $25.78^{\mathrm{a}} \pm 1.02$ & $6.05^{\mathrm{b}} \pm 0.73$ \\
Strongyles/Trichuris & $8.64^{\mathrm{a}} \pm 0.54$ & $22.89^{\mathrm{b}} \pm 1.12$ & $6.04^{\mathrm{b}} \pm 0.78$ \\
Strongyloides papillosus/Trichuris & $8.98^{\mathrm{a}} \pm 0.74$ & $22.19^{\mathrm{b}} \pm 1.52$ & $6.08^{\mathrm{ab} \pm 0.87}$ \\
\hline
\end{tabular}

a, b Row means with different superscripts differs significantly ( $p<0.05)$; FEC: Fecal Egg Count; PCV: Packed Cell Volume; MCH: Mean Corpuscular Hemoglobin

Table 3: Pearson's moment correlation test between the gastro-intestinal parasites intensity and the hematological parameters in South African communal goats

\begin{tabular}{llll}
\hline & Hemoglobin concentration $(\mathrm{g} / \mathrm{dL})$ & PCV $(\%)$ & Mean corpuscular hemoglobin $(\mathrm{pg})$ \\
\hline Overall FEC & $-0.45^{* *}$ & $-0.55^{* *}$ & $-0.13^{*}$ \\
Strongyles & $-0.52^{* *}$ & $-0.70^{* *}$ & $-0.12^{\mathrm{NS}}$ \\
S. papillosus & $-0.06^{\mathrm{NS}}$ & $-0.39^{*}$ & $-0.14^{\mathrm{NS}}$ \\
Trichuris & $-0.66^{* * *}$ & $-0.59^{* *}$ & $-0.21^{*}$ \\
Eimeria & $-0.07^{\mathrm{NS}}$ & $-0.26^{*}$ & $-0.50^{* *}$ \\
Moniezia & $0.02^{\mathrm{NS}}$ & $0.17^{\mathrm{NS}}$ & $0.19^{*}$ \\
\hline
\end{tabular}

$* p>0.05, * * p>0.01, * * * p>0.001$, NS: Not Significant $(p>0.05)$; FEC: Fecal Egg Count 


\section{Discussion}

The intensity of infection for the strongyles, S. papillosus, Trichuris, Eimeria and Moniezia, spp. was found to be lower in the LFEC phenotype than in the intermediate FEC and HFEC phenotype. This could be attributed to the fact that resistance to one GIP species was accompanied by resistance to some other GIPs or vice-versa (Behnke et al., 2006). However, similar results had been previously reported, where there was a positive relationship between resistance to different GIPs in Nigerian West African Dwarf goats (Behnke et al., 2006) and INRA sheep (Gruner et al., 2003). Major effects of higher GIP infections on animals are severe anemia (Burden et al., 2010) along with other hematological (Rasool et al., 1995) and biochemical disturbances (Moudgil et al., 2017). Furthermore, the hematological parameters were also lower in the HFEC phenotype compared to the uninfected group and LFEC phenotype, attributed to a greater load of GIPs sucking a substantial amount of blood, therefore, lowering these parameters. These findings accord with previous reports that the higher GIP infection intensity especially $\mathrm{H}$. contortus leads to lower PCV (Ameen et al., 2010; Saddiqi et al., 2010; 2012; Moudgil et al., 2017) and $\mathrm{Hgb}$ concentration (Audu et al., 2018) in animals. Noteworthy, H. contortus infection in West African Dwarf goats resulted in a normochromic normocytic anemia attributed to blood loss caused by this GIP (Ameen et al., 2010). However, contrary to the present findings, Ameen et al. (2010) observed similar normal $\mathrm{Hgb}$ concentrations and increased $\mathrm{MCH}$ values between the infected and uninfected West African Dwarf goats. The difference could be attributed to the breed and age of goat and more importantly, the prepatent period and duration of infection which consequently determines the response to infection. In parasitological sense, the prepatent period in GIPs infection is defined as the time elapsed between the infection and the first appearance of eggs in the feces (Hansen and Perry, 1994), which varies with the infection route, sex, age and degree of acquired resistance of the host (Ameen et al., 2010). Animals may acquire immunity/resistance to the parasite through the frequent challenge (Shah-Fischer and Say, 1989; Singh et al., 2015). Furthermore, Radostits et al. (2010) reported a difference in hematological parameters between weeks of post-infection in ruminants. Anemic goats with normal $\mathrm{MCH}$ values are referred to as normocytic normochromic. Therefore, the normocytic normochromic anemia observed here is consistent with other reports of anemia in cattle with strongyles infection (Audu et al., 2018).

The reduction in the $\mathrm{MCH}$ of the HFEC phenotyped goats could be due to direct reduction in the level of $\mathrm{Hgb}$ concentration observed which might be ascribed to deficiency of iron (Cole et al., 1997; Khan et al., 2010) attributed to blood loss due to GIPs infection (Soulsby, 1986; Katoch and Mandial, 2003; Radostits et al., 2010). The depletion of iron hypothesized might also be due to the rapid depletion of iron stores by the bone marrow for $\mathrm{Hgb}$ production (Schalm, 1975; Khan et al., 2010). The observed similar PCV and MCH of the uninfected group and LFEC phenotyped goats depicts that low infection intensity by the GIPs does not alter these hematological parameters. Reduced hematological parameters in IFEC and HFEC phenotyped compared to uninfected goats were also observed in cattle infected by the GIPs, especially the Bunostomum and Trichostrongylus spp. (Singh et al., 2014).

The findings that the infection status (single vs coinfection) influences the hemoglobin and PCV concurs with earlier reports (Graham et al., 2007; Vaumourin et al., 2015) that interaction between concomitant parasites complicate the clinical outcome of the infected hosts and should be taken into consideration in any study that investigates disease under field conditions and disease management programme. Several mechanisms of direct and indirect interaction between co-infecting parasites have been proposed, but results remain ambiguous (Petney and Andrews, 1998; Murphy et al., 2013; Vaumourin et al., 2015). These interactions may be synergistic or antagonistic, wherein, one parasite can improve the immune response to a second parasite through cross-immunity (negative interaction) (Tabel et al., 2013), or alternatively cause immuno-suppression (positive interaction) (Cox, 2001; Pedersen and Fenton, 2007). Such interactions can have important impacts on animal health since they can modify host susceptibility, infection duration and transmission risks (Petney and Andrews, 1998; Graham et al., 2007; Vaumourin et al., 2015). The literature on the structural or functional changes in animals with mixed infections is scanty (Brown et al., 1989; Poulin, 2007) or making a logical judgment on the basis of circumstantial evidence and prior conclusions by comparing single to mixed infections than assessing the contributions of the single strains in the mixed infection.

Eimeria spp. single infection caused a slight decrease of PCV and hemoglobin of the goat population which was not clinically significant from those free of any GIP and may be due to the level of dehydration due to diarrhea. It would be interesting to investigate the association between Eimeria infection and other clinical parameters such as the presence or absence of diarrhea, in this population.

In the present study, the PCV strongly correlated with the FECs for the strongyles, S. papillosus, Trichuris and Eimeria spp. depicting that it can be used as a predictor of infection intensity by these GIPs. The present findings that the PCV has a negative significant correlation with overall FEC and strongyles confirms earlier reports (Kaplan, 2004; Scheuerle et al., 2010). The present findings also concur with previous reports that the FEC 
(Hayward et al., 2014) and PCV (Saddiqi et al., 2012; Zvinorova, 2017) are the most important phenotypic indicators of infection intensity and host resistance. Low values of PCV are commonly associated with high FEC attributed to the adult parasites sucking a substantial amount of blood from the abomasum (Saddiqi et al., 2010; 2012). Practically, resistant animals show low FEC and high PCV.

The strongyles are recognized as active blood suckers in the stomach and intestine, subsequently, its infection causes a decrease in the value of $\mathrm{Hgb}$ concentration and PCV (Kumar et al., 2015). The average blood loss due to $\mathrm{H}$. contortus infection is $0.03 \mathrm{ml} /$ parasite/day (Bordoloi et al., 2012). The insignificant relationship between the $\mathrm{MCH}$ and the strongyles and S. papillosus intensity observed in the present study depicts that $\mathrm{MCH}$ is not a valuable indicator for the intensity and resistance against the strongyles and S. papillosus. The present findings that there is an insignificant relationship between the $\mathrm{MCH}$ and the strongyles and S. papillosus intensity concurs with earlier report wherein the lack of significance decrease in the MCH of infected animals (sheep) compared to uninfected animals had also been reported (Kumar et al., 2015).

The findings that the $\mathrm{MCH}$ has a moderate and negative significant correlation with the intensity for the Eimeria depicts that the $\mathrm{MCH}$ is of great value and can be used as a valuable predictor for the Eimeria intensity in South African communal goats. Also, the observed moderate and negative significant correlation between the $\mathrm{Hgb}$ concentration and FECs for strongyles and Trichuris spp. depicts that hemoglobin concentration is also of great importance and can be used as a good predictor of infection intensity for these GIPs. The observed strong and insignificant relationship between the Moniezia spp. infection intensity with the $\mathrm{Hgb}$ concentration and PCV significantly underscore the value of these hematological parameters as potential parameters for assessing the intensity of Moniezia spp. in goats. However, there is a paucity of information on the use of $\mathrm{Hgb}$ concentration and $\mathrm{MCH}$ as phenotypic predictors for GIP infection intensity in animals.

\section{Conclusion}

The results suggest that interactions between concomitant GIP complicates the clinical outcome of the infected goats and should be taken into consideration in any study that investigates disease under field conditions and disease management programme. The results suggest that the PCV and infection intensity are reliable measures for resistance against strongyles, S. papillosus, Trichuris and Eimeria spp. The Hgb concentration and infection intensity can be used as response phenotypic predictors for resistance against strongyles and Trichuris spp. The MCH and infection intensity can be used as response phenotypic predictors for resistance against Eimeria, Trichuris and Moniezia spp. Thus, these response phenotypic predictors can be used as selection criteria for the GIP resistant South African communal indigenous goats.

\section{Acknowledgement}

The authors are grateful to the communal goat farmers and veterinary officers in Kwa-Zulu Natal, Limpopo and Mpumalanga provinces for their assistance and participation in this study.

\section{Funding Information}

This work was partially supported by the Tshwane University of Technology Postgraduate Scholarship; and the National Research Foundation, South Africa (Grants: 112055, 121138 and KIC: 115724) and Erasmus+ $(65 / 2020 I)$

\section{Author's Contributions}

Takalani Judas Mpofu: Participated in all experiments, coordinated the data-analysis and contributed to the writing of the manuscript.

Khathutshelo Agree Nephawe and Bohani Mtileni: Involved in the design of the study, coordinated all the work and constructive revision of manuscript.

\section{Ethics}

This article is original and contains unpublished material. The corresponding author confirms that all of the other authors have read and approved the manuscript and no ethical issues involved.

\section{References}

Aboshady, H.M., M.J. Stear, A. Johansson, E. Jonas and J.C. Bambou, 2020. Immunoglobulins as Biomarkers for gastrointestinal nematodes resistance in small ruminants: A systematic review. Scientific Rep., 10: 7765-7765. DOI: 10.1038/s41598-020-64775-x

Adeyemi, M.T., O.A. Morenikeji, B.O. Emikpe and T.A. Jarikre, 2017. Interactions between gastrointestinal parasitism and pneumonia in Nigerian goats. J. Parasitic Dis., 41: 726-733.

DOI: $10.1007 / \mathrm{s} 12639-017-0878-6$

Ameen, S.A., R.A. Joshua, O.S. Adedeji, L.O. Ojedapo and S.R. Amao, 2010. Experimental studies on gastro-intestinal nematode infection; the effects of age on clinical observations and haematological changes following Haemonchus contortus infection in West African Dwarf (WAD) goats. World J. Agric. Sci., 6: 39-43. 
Asha, A. and B. Chebo, 2015. Epidemiological study on gastrointestinal tract helminthosis of small ruminants in Dawuro zone. Ethiop. Vet. J., 19: 63-82. DOI: $10.4314 /$ evj.v19i1.9

Aster, J.C., 2004. Anaemia of Diminished Erythropoiesis. In: Robbins and Cotran Pathologic Basis of Disease, Kumar, V., A.K. Abbas, N. Fausto, S.L. Robbins and R.S. Cotran (Eds.), Saunders Co, Philadelphia, pp: 638-649.

Audu, Y., Y.M. Lekko, M.B. Umar, E.S. Mshellia and H.P. Mana, 2018. Effect of strongyle on haematological parameters of cattle in Maiduguri, Borno State, Nigeria. IOSR- J. Agric. Vet. Sci., 11: 60-63.

Aumont, G., L. Gruner and G. Hostache, 2003. Comparison of the resistance to sympatric and allopatric isolates of Haemomchus contrortus of Black Belly sheep in Guadeloupe (FWI) and INRA 401 sheep in France. Vet. Parasitol., 116: 139-150. DOI: 10.1016/S0304-4017(03)00259-0

Awodi, S., J.O. Ayo, A.D. Atodo and T. Dzende, 2005. Some haematological parameters and the erythrocyte osomotic fragility in the laughing dove (Streptopella senegalensis) and the village weaner bird (Ploceus cucullatus). Proceedings of the 10th Annual Conference of Animal Science Association of Nigeria, (SAN' 05), pp: 384-387.

Baker, R.L., 1999. Genetic resistance to endoparasites in sheep and goats. A review of genetic resistance to gastrointestinal nematode parasites in sheep and goats in the tropics and evidence for resistance in some sheep and goat breeds in sub-humid coastal Kenya. Anim. Genetic Resources Inform., 24: 13-30. DOI: $10.1017 /$ S1014233900001103

Behnke, J.M., S.N. Chiejina, G.A. Musongong, B.B. Fakae and R.C. Ezeokonkwo et al., 2006. Naturally occurring variability in some phenotypic markers and correlates of haemonchotolerance in West African Dwarf goats in a sub-humid zone of Nigeria. Vet. Parasitol., 131: 180-191. DOI: 10.1016/j.vetpar.2006.04.017

Benavides, M.V., T.S. Sonstegrard and C. Van Tassell, 2016. Genomic regions associated with sheep resistance to gastrointestinal nematodes. Trends Parasitol., 32: 47-480. DOI: 10.1016/j.pt.2016.03.007

Bishop, S.C. and C. Morris, 2007. Genetics of disease resistance in sheep and goats. Small Rum. Res., 70: 48-59. DOI: 10.1016/j.smallrumres.2007.01.006

Bishop, S.C. and M.J. Stear, 1999. Genetic and epidemiological relationships between productivity and disease resistance: Gastro-intestinal parasite infection in growing lambs. Anim. Sci., 69: 515-524. DOI: 10.1017/S1357729800051365

Blackie, S., 2014. A review of the epidemiology of gastrointestinal nematodes infections in sheep and goats in Ghana. J. Agric. Sci., 6: 109-118.

DOI: 10.5539/jas.v6n4p109
Bordoloi, G., R. Jas and J.D. Ghosh, 2012. Changes in the haemato-biochemical pattern due to experimentally induced haemonchosis in Sahabadi sheep. J. Parasitic Dis., 36: 101-105. DOI: 10.1007/s12639-011-0079-7

Bressani, F.A., P.C. Tizioto, R. Giglioti, S.L.C. Meirelles and R. Coutinho et al., 2014. Single nucleotide polymorphisms in candidate genes associated with gastrointestinal nematode infection in goats. Genet. Molecular Res., 13: 8530-8536. DOI: $10.4238 / 2014$.October.20.29

Brown, A., M. Bennett and C.J. Gaskell, 1989. Fatal poxvirus infection in association with FIV infection. Vet. Rec., 124: 19-20.

Burden, F.A., N. Du Toit, M. Hernandez-Gil, O. PradoOrtiz and A.F. Trawford, 2010. Selected health and management issues facing working donkeys presented for veterinary treatment in rural Mexico: Some possible risk factors and potential intervention strategies. Tropical Animal Health Product., 42: 597-605. DOI: 10.1007/s11250-009-9462-0

Bush, A.O., K.D. Lafferty, J.M. Lotz and A.W. Shostak, 1997. Parasitology meets ecology on its own terms: Margolis et al. revisited. J. Parasitol., 83: 575-583. DOI: $10.2307 / 3284227$

Cattadori, I.M., B. Boag and P.J. Hudson, 2008. Parasite co-infection and interaction as drivers of host heterogeneity. Int. J. Parasitol., 38: 371-380.

DOI: 10.1016/j.ijpara.2007.08.004

Chineke, C.A., A.G. Ologun and C.O.N. Ikeobi, 2006. Haematological parameters in rabbit breeds and crosses in humid tropics. Pak. J. Biol. Sci., 9: 2102-2106. DOI: 10.3923/pjbs.2006.2102.2106

Cole, D.J., A.J. Roussel and M.S. Whitney, 1997. Interpreting a bovine $\mathrm{CBC}$ : Collecting a sample and evaluating the erythron. Vet. Med., 5: 460-468.

Cox, F.E., 2001. Concomitant infections, parasites and immune responses. Parasitology, 122: S23-S38. DOI: $10.1017 / \mathrm{S} 003118200001698 \mathrm{X}$

Dominik, S., 2005. Quantitative trait loci for internal nematode resistance in sheep: A review. Genet. Select. Evolut., 37: 83-96. DOI: $10.1186 / 1297-9686-37-S 1-S 83$

Erez, M.S. and E. Kozan, 2018. Anthelmintic resistance in farm animals. Kocatepe Vet. J., 11: 322-330.

Foriet, W., 1999. Veterinary Parasitology Reference Manual. 4th Edn., Wiley Blackwell, New York, ISBN-10: 0813823773, pp:196.

González, J.F., Á. Hernández, E.N.T. Meeusen, F. Rodríguez and J.M. Molina et al., 2011. Fecundity in adult Haemonchus contortus parasites is correlated with abomasal tissue eosinophils and $\gamma \delta \mathrm{T}$ cells in resistant Canaria Hair Breed sheep. Vet. Parasitol., 178: 286-292. DOI: 10.1016/j.vetpar.2011.01.005 
Graham, A., I.M. Cattadori, J. Lloyd-Smith, M. Ferrari and O.N. Bjornstad, 2007. Transmission consequences of co-infection: Cytokines writ large? Trends Parasitol., 23: 284-291.

Gruner, L., G. Aumont, T. Getachew, J.C. Brunel and C. Pery et al., 2003. Experimental infection of Black Belly and INRA 401 straight and crossbred sheep with trichostrongyle nematode parasites. Vet. Parasitol., 116: 239-249.

DOI: 10.1016/j.vetpar.2003.07.005

Gruner, L., J. Bouix and J.C. Brunel, 2004. High genetic correlation between resistance to Haemonchus contortus and Trichostrongylus colubriformis in INRA 401 sheep. Vet. Parasitol., 119: 51-58.

DOI: 10.1016/j.vetpar.2003.10.014

Hansen, J. and B. Perry, 1994. Epidemiology, Diagnosis and Control of Helminth Parasites of Ruminants. 2nd Edn., ILRAD, Nairobi.

Hassan, N.M.F., T.K. Farag, N.M.T. Abu El Ezz and H.A.A. Abou-Zeina, 2019. Prevalence assessment of gastrointestinal parasitic infections among goats in Giza Governorate, Egypt. Bull. Nat. Res. Centre, 43: 127-127.

DOI: $10.1186 / \mathrm{s} 42269-019-0151-5$

Hayward, A.D., D.H. Nussey, A.J. Wilson, C. Berenos and J.G. Pilkington et al., 2014. Natural selection on individual variation in tolerance of gastrointestinal nematode infection. PLOS Biol., 12: e1001917-e1001917.

DOI: 10.1371/journal.pbio.1001917

Hepworth, K., M. Neary and T. Hutchens, 2006. Managing internal parasitism in sheep and goats. Purdue University Cooperative Extension Service, West Lafayette, Indiana.

Jegede, O.C., A.A. Adejoh, S.S. Obeta and O.D. Olayemi, 2015. Gastrointestinal parasites of sheep and goats in gwagwalada area council, federal capital territory, Abuja, Nigeria; with a special reference to sex, breed and age. Alexandria J. Vet. Sci., 46: 170-176. DOI: 10.5455/ajvs. 177135

Kaplan, R.M., 2004. Drug resistance in nematodes of veterinary importance: A status report. Trends Parasitol., 20: 477-481. DOI: 10.1016/j.pt.2004.08.001

Katoch, A. and R.K. Mandial, 2003. Clinicohaematological, biochemical and therapeutic studies on anaemia in cattle. Indian J. Vet. Med., 23: 75-78.

Kelley, J.M., T.P. Elliott, T. Beddoe, G. Anderson and P. Skuce et al., 2016. Current threat of triclabendazole resistance in Fasciola hepatica. Trends Parasitol., 32: 458-469. DOI: 10.1016/j.pt.2016.03.002

Khan, I.A., A. Khan, A. Hussain, A. Riaz and A. Aziz, 2010. Hemato-biochemical alterations in crossbred cattle affected with Bovine theileriosis in semi arid zone. Pak. Vet. J., 31: 137-140.
Kheirandish, R., S.R. Nourollahi-Fard and Z. Yadegari, 2014. Prevalence and pathology of coccidiosis in goats in southeastern Iran. J. Parasitic Dis., 38: 27-31. DOI: $10.1007 / \mathrm{s} 12639-012-0186-0$

Kumar, S., K.K. Jakhar, S. Singh, S. Potliya and K. Kumar et al., 2015. Clinico-pathological studies of gastrointestinal tract disorders in sheep with parasitic infection. Vet. World, 8: 29-32.

DOI: 10.14202/vetworld.2015.29-32

Maqbool, I., Z.A. Wani, R.A. Shahardar, I.M. Allaie and M.M. Shah, 2017. Integrated parasite management with special reference to gastro-intestinal nematodes. J. Parasitic Dis., 41: 1-8.

DOI: $10.1007 / \mathrm{s} 12639-016-0765-6$

MiniTab 17, 2017. MiniTab 17 Statistical Software. [Computer Software]. Minitab, Inc., State College, PA. www.minitab.com

Moudgil, A.D., A. Sharma, M.S. Verma, R. Kumar and P.K. Dogra et al., 2017. Gastrointestinal parasitic infections in Indian Gaddi (goat) breed bucks: Clinical, hemato-biochemical, parasitological and chemotherapeutic studies. J. Parasitic Dis., 41: 1059 1065. DOI: 10.1007/s12639-017-0934-2

Mpofu, T.J., K.A. Nephawe and B. Mtileni, 2020. Prevalence of gastrointestinal parasites in communal goats from different agro-ecological zones of South Africa. Vet. World, 13: 26-32.

DOI: $10.14202 /$ vetworld.2020.26-32

Murphy, L., A.K. Pathak and I.M. Cattadori, 2013. A coinfection with two gastrointestinal nematodes alters host immune responses and only partially parasite dynamics. Parasite Immunol., 35: 421-432.

DOI: $10.1111 /$ pim. 12045

Pedersen, A.B. and A. Fenton, 2007. Emphasizing the ecology in parasite community ecology. Trends Ecol. Evolut., 22: 133-139.

DOI: $10.1016 /$ j.tree.2006.11.005

Peters, S.O., H.H. Gunn, I.G. Imumorin, B.O. Agaviezor and C.O. Ikeobi, 2011. Haematological studies on frizzled and naked neck genotypes of Nigerian native chickens. Tropical Anim. Health Product., 43: 631-638.

DOI: $10.1007 / \mathrm{s} 11250-010-9743-7$

Petney, T.N. and R.H. Andrews, 1998. Multiparasite communities in animals and humans: frequency, structure and pathogenic significance. Int. J. Parasitol., 28: 377-393. DOI: 10.1016/S0020-7519(97)00189-6

Poulin, R., 2007. Evolutionary Ecology of Parasites. 2nd Edn., Princeton University Press, Princeton, New Jersey, USA.

Radostits, O.M., C.C. Gay, K.W. Hinchcliff and P.D. Constable, 2010. Veterinary Medicine: A Textbook of the Diseases of Cattle, Horses, Sheep, Pigs and Goats. 10th Edn., W.B. Saunders, London. 
Rasool, G., Z. Iqbal, M.N. Khan and B. Hayat, 1995. Haematological disturbances associated with haemonchosis in sheep. Pak. Vet. J., 15: 159-162.

Risso, A., J.D. Kessler, V.S. Soriano, M.L.A. Nunes and G. Machado et al., 2015. Influence of pathological conditions caused by gastrointestinal parasites infection on pregnant ewe's behavior. Acta Scientiae Vet., 43: 1283-1283.

Rodríguez, A.V., V. Goldberg, H. Viotti and G. Ciappesoni, 2015. Early detection of Haemonchus contortus infection in sheep using three different faecal occult blood tests. Open Vet. J., 5: 90-97.

Saddiqi, H.A., M. Sarwar, Z. Iqbal, M. Nisa and M.A. Shahzad, 2012. Markers/parameters for the evaluation of natural resistance status of small ruminants against gastrointestinal nematodes. Animal, 6: 994-1004. DOI: $10.1017 / \mathrm{S} 1751731111002357$

Saddiqi, H.A., Z. Iqbal, M.N. Khan, M. Sarwar and G. Muhammad et al., 2010. Evaluation of three Pakistani sheep breeds for their natural resistance to artificial infection of Haemonchus contortus, Short communication. Vet. Parasitol., 168: 141-145.

DOI: $10.1016 /$ j.vetpar.2009.10.022

Schalm, O.W., 1975. Differential diagnosis of anaemia in animals. J. Am. Vet. Med. Assoc., 161: 1269-1275.

Scheuerle, M., M. Mahling, J. Muntwyler and K. Pfister, 2010. The accuracy of the FAMACHA@ method in detecting anaemia and haemonchosis in goat flocks in Switzerland under field conditions. Vet. Parasitol., 170: 71-77.

DOI: 10.1016/j.vetpar.2010.01.035

Shah-Fischer, M. and R. Say, 1989. Manual of tropical veterinary parasitology. CAB International; the Technical Center for Agricultural and Rural Cooperation (CTA).

Singh, A.K., G. Das, B. Roy, S. Nath and R. Naresh et al., 2015. Prevalence of gastro-intestinal parasitic infections in goat of Madhya Pradesh, India. J. Parasitic Dis., 39: 716-719. DOI: $10.1007 / \mathrm{s} 12639-014-0420-\mathrm{z}$

Singh, E., P. Kaur, L.D. Singla and M.S. Bal, 2017. Prevalence of gastrointestinal parasitism in small ruminants in western zone of Punjab, India. Vet. World, 10: 61-66. DOI: 10.14202/vetworld.2017.61-66

Singh, J., S.K. Gupta, R. Singh and S.A. Hussain, 2014. Etiology and haemato-biochemical alterations in cattle of Jammu suffering from anaemia. Vet. World, 7: 49-51. DOI: 10.14202/vetworld.2014.49-51
Soulsby, E.J.L., 1986. Helminths, Arthropods and Protozoa of Domesticated Animals. 7th Edn., The English Language Book Society, Bailliere Tindall, London, UK, pp: 285.

Squire, S.A., I.D. Robertson, R. Yang, I. Ayi and U. Ryan, 2019. Prevalence and risk factors associated with gastrointestinal parasites in ruminant livestock in the Coastal Savannah zone of Ghana. Acta Tropica. DOI: 10.1016/j.actatropica.2019.105126

Stear, M.J., K. Bairden, G.T. Innocent, S. Mitchell and S. Strain et al., 2004. The relationship between IgA activity against 4th-stage larvae and densitydependent effects on the number of 4th-stage larvae of Teladorsagia circumcincta in naturally infected sheep. Parasitology, 129: 363-369.

DOI: $10.1017 / \mathrm{S} 0031182004005736$

Tabel, H., G. Wei and H.J. Bull, 2013. Immunosuppression: Cause for failures of vaccines against African trypanosomiasis. PLoS Negl. Trop. Dis., 7: e2090-e2090.

Thrusfield, M., 1997. Veterinary Epidemiology. 2nd Edn. Blackwell Sciences, Sussex, Oxford, pp: 182.

Van Wyk, J.A., J. Cabaret and L.M. Michael, 2004. Morphological identification of nematodes of small ruminants and cattle simplified. Vet. Parasitol., 119: 277-306. DOI: 10.1016/j.vetpar.2003.11.012

Vaumourin, E., G. Vourc'h, P. Gasqui and M. Vayssier-Taussat, 2015. The importance of multiparasitism: examining the consequences of coinfections for human and animal health. Parasite. Vector., 8: 545-545.

Verma, R., D. Sharma, S. Paul, G. Kumaresan and M. Dige et al., 2018. Epidemiology of common gastrointestinal parasitic infections in goats reared in semi-arid region of India. J. Anim. Res., 8: 39-45.

Zajac, M. and G. Conboy, 2006. Veterinary Clinical Parasitology. 7th Edn. Blackwell Publishing, Sussex.

Zvinorova, P.I., 2017. A genome-wide association study on mechanisms underlying genetic resistance to gastrointestinal parasites in goats, Zimbabwe. PhD Thesis, Stellenbosch University, Western Cape, South Africa. 